0413 VIOLENCE PERPETRATED BY HOSPITAL PATIENTS AND VISITORS (TYPE II) AGAINST "SITTERS"

${ }^{1}$ Ashley Schoenfisch, ${ }^{2}$ Lisa Pompeii, ${ }^{1}$ Hester Lipscomb, 'John Dement. 'Duke University Medical Center, Durham, North Carolina, USA; ${ }^{2}$ University of Texas Health Sciences Center, Houston, Texas, USA

\subsection{6/oemed-2014-102362.163}

Objectives Hospital sitters provide continuous observation of patients at risk of harming themselves or others. This study examined violence perpetrated by patients/visitors (type II) against hospital sitters in two US healthcare systems.

Method Anonymous, cross-sectional survey data were collected from staff, including 41 sitters, across six hospitals to characterise the magnitude of and circumstances surrounding type II violence. Focus groups and interviews $(n=17)$ provided contextual details.

Results Unit/float pool aides, patient care attendants, unit secretaries, and contract employees served as sitters. Compared to other staff, sitters had higher 12-month prevalences of physical assault $(61 \% ; 11 \%)$, physical threat $(63 \% ; 18 \%)$, and verbal abuse (73\%;37\%). Sitters were more likely to experience a patient (rather than visitor) perpetrator $(94 \% ; 76 \%)$, have a weapon (s) used against them $(72 \% ; 31 \%)$, be alone with the perpetrator $(65 \% ; 40 \%)$, perceive intent to harm $(33 \% ; 17 \%)$, and feel frightened about their personal safety $(61 \% ; 38 \%)$. Sitters often reported events verbally to unit staff and rarely through official channels (e.g., first report of injury). In focus groups and interviews, sitters and staff indicated their need for clarification of sitters' roles regarding patient care and sitter well-being (e.g., calling for assistance, taking lunch/restroom breaks), training of sitters in personal safety and patient/visitor de-escalation, and methods to inform sitters and other staff of patient/visitor conditions and behaviours.

Conclusions The burden of type II violence among hospital sitters is high. Policies surrounding sitters' roles and violence prevention training - supported by hospital and unit management are needed. Continued efforts to describe the safety and health of this workgroup are warranted.

\section{CAREX CANADA'S EWORK: DEVELOPING INNOVATIVE TOOLS FOR STATISTICS ON CANADIANS' OCCUPATIONAL EXPOSURE TO CARCINOGENS}

${ }^{1}$ Calvin Ge, ${ }^{2}$ Cheryl Peters, ${ }^{1}$ Alison Palmer, ${ }^{3}$ Paul Demers. 'Simon Fraser University, Burnaby, BC, Canada; 'University of British Columbia, Vancouver, BC, Canada; ${ }^{3}$ Occupational Cancer Research Centre, Toronto, ON, Canada

\subsection{6/oemed-2014-102362.164}

Objectives To enhance access to CAREX Canada's occupational exposure estimates by creating and demonstrating two electronic tools, eWORK Excel and eWORK Online. Both tools allow users to explore CAREX results by occupation, industry, exposure level, and carcinogen. Results generated by the tools are dynamic, customizable, and tailored to the user's interest.

Method eWORK Excel was developed in Microsoft Excel with the PowerPivot add-on. eWORK Online was developed using a data visualisation software called Tableau Public. Data inputs (prevalence and level of exposure estimates to known and suspected carcinogens) were developed using CAREX methods established in the European Union and enhanced for the Canadian context.

Results Two functional tools, eWORK Excel and eWORK Online, are already completed and beta testing is underway. Future deliverables include upgrading the tools with additional data and capabilities, and refining tool features based on testing feedback. Target audiences differ for our two eWORK tools. eWORK Excel is aimed at savvy data users such as researchers in occupational hygiene and epidemiology. eWORK Online is for users who prefer quick, simple, yet high quality statistics on occupational exposures to various carcinogens. Target groups for eWORK Online include physicians, policymakers, occupational health and safety professionals, and labour organisations.

Conclusions The overall goal of the CAREX Canada project is to help reduce exposure to carcinogens in Canadian workplaces by providing scientific evidence on exposure patterns and concentrations for policymakers and other important stakeholders. eWORK Excel and eWORK Online are innovate tools which play a key role in effective communication of our research results.

\section{EVALUATION OF AN AUDIT-BASED OCCUPATIONAL HEALTH AND SAFETY RECOGNITION PROGRAM ON FIRM WORK-INJURY RATES IN BRITISH COLUMBIA, CANADA}

${ }^{1,2}$ Christopher McLeod. ${ }^{1}$ University of British Columbia, Vancouver, Canada; ${ }^{2}$ Institute for Work and Health, Toronto, Canada

\subsection{6/oemed-2014-102362.165}

Objectives In 2003 British Columbia's occupational health and safety (OHS) regulator implemented a voluntary audit-based OHS recognition program in select industrial sectors. Firms achieving OHS certification received a rebate on workers' compensation premiums. This study evaluated the effect of OHS certification on firm work-injury rates for the years 2004 to 2011.

Method A cohort of certified (intervention) and non-certified (control) firms was derived from workers' compensation claims records from 2000 to 2011. Firms were drawn from the industrial sectors covered by the OHS program and had to have paid workers' compensation premiums for at least three years during the study period. A difference-in-difference evaluation approach using random-effects Poisson regression was implemented that accounted for the difference in baseline injury risk and the change in injury risk over time between the intervention and control group. Estimates were adjusted for industrial sector, firm size, firm tenure and industrial sector average injury risk. Outcomes investigated were loss-time injuries and a subset of more serious work injuries.

Results The intervention group included 4392 firms who achieved OHS certification between 2003 and 2010. These firms had similar baseline loss-time (IRR: 1.04 95\% CI: 1.00-1.08) and serious injury rates (IRR: 0.99 95\% CI: 0.94-1.04) compared to controls. Safety certification was associated with a decline in the loss-time (IRR: $0.9295 \%$ CI: 0.90-0.94) and serious injury rate (IRR: 0.88 95\% CI: 0.85-0.92).

Conclusions Voluntary audit-based OHS certification was associated with a $8 \%$ and $12 \%$ reduction in loss-time and serious injuries British Columbia between 2004 and 2011. 